\title{
Effects of Chrysin Against Isoniazid-Induced Lung Injury in Rats
}

\author{
Sefa KÜÇÜKLER ${ }^{*}$, Selçuk ÖZDEMİR², Selim ÇOMAKLI ${ }^{3}$, Fatih Mehmet KANDEMİR \\ ${ }^{1}$ Department of Biochemistry, Faculty of Veterinary Medicine, Ataturk University, Erzurum, Turkey \\ ${ }^{2}$ Department of Genetics, Faculty of Veterinary Medicine, Atatürk University, Erzurum, Turkey \\ ${ }^{3}$ Department of Pathology, Faculty of Veterinary Medicine, Atatürk. University, Erzurum, Turkey
}

\begin{abstract}
The aim of the study was to investigate the effects of chrysin $(\mathrm{CH})$, one of the natural flavonoids, against isoniazid lung damage caused by isoniazid (INH), which was widely used in the treatment of tuberculosis. Male Sprague-Dawley rats were randomly divided into five groups: a control group, INH-treated group, $\mathrm{CH}$ alone treated group $50 \mathrm{mg} / \mathrm{kg}$, INH $+\mathrm{CH} 25 \mathrm{mg} / \mathrm{kg}$ treated group, and INH+ CH $50 \mathrm{mg} / \mathrm{kg}$ treated group. It was determined that INH caused oxidative damage by decreasing antioxidant enzyme activities such as glutathione peroxidase (GPx), superoxide dismutase (SOD), and catalase (CAT) and increasing lipid peroxidation (LPO). In addition, it was found that the administration of $\mathrm{CH}$ to INH-treated rats increased GSH level and antioxidant enzyme activities, and decreased lipid peroxidation. It was observed that the nuclear factor erythroid 2 related factor 2 (Nrf-2) and oxygenase-1 (HO-1) expression levels were up-regulated in the INH-treated group, and the expression of NF- $x \mathrm{~B}$ increased in the INH-treated group in the immunohistochemical examination, and the $\mathrm{CH}$ administration, on the other hand, decreased the levels of these markers. Taken together, these results suggested that $\mathrm{CH}$ had beneficial effects in INH-induced lung toxicity by maintaining the oxidant-antioxidant balance and decreasing NF- $x \mathrm{~B}, \mathrm{Nrf}-2$, and HO-1 expressions.
\end{abstract}

Keywords: Chrysin, Isoniazid, Lung, Oxidative Stress.

\section{Ratlarda İzoniazid Kaynaklı Akciğer Hasarına Karşı Krisinin Etkileri}

ÖZ

Bu çalışmanın amacı; tüberküloz tedavisinde yaygın olarak kullanılan izoniazid (İZN) kaynaklı akciğer hasarına karşı doğal flavonoidlerden olan krisin (KRS)'in etkilerinin araştırılmasıdır. Çalışmada Spraque Dawley cinsi 35 adet erkek rat rastgele 5 gruba ayrıldı: Kontrol grubu, IZN uygulanan grup, KRS $50 \mathrm{mg} / \mathrm{kg}$ uygulanan grup, IZN+ KRS $25 \mathrm{mg} / \mathrm{kg}$ uygulanan grup ve IZZN+ KRS $50 \mathrm{mg} / \mathrm{kg}$ uygulanan grup. İZN'nin glutatyon peroksidaz (GPx), süperoksit dismutaz (SOD) ve katalaz (KAT) gibi antioksidan enzim aktivitelerini ve glutatyon (GSH) düzeylerini azaltıp, lipid peroksidasyonunu (LPO) artırarak oksidatif hasara neden olduğu belirlendi. Ayrıca İZN ile kombine uygulanan KRS uygulamasının GSH seviyesini ve antioksidan enzim aktivitelerini artırdı̆̆ı, lipid peroksidasyonunu ise azalttı̆̆ ettiği tespit edildi. Çalısmada incelenen nükleer faktör eritroid 2 ile ilişkili faktör 2 (Nrf-2) ve hem oksijenaz-1 (HO-1) seviyelerinin İZN grubunda gen ekspresyonu düzeyinde, nükleer faktör kappa $\mathrm{B}$ (NF- $x \mathrm{~B})$ ekspresyonunu ise immunhistokimyasal incelemede arttığ tespit edilmiş, buna karşın KRS uygulamasının bu belirteçlerin düzeylerinde azalmaya neden olduğu gözlenmiştir. Birlikte ele alındığında, bu sonuçlar KRS'in oksidan-antioksidan dengesini koruyarak ve NF- $x \mathrm{~B}$, Nrf-2 ve HO-1 ekspresyonlarını azaltarak IZN'nin neden olduğu akciğer toksisitesinde faydalı etkilere sahip olduğunu düşündürmektedir.

Anahtar Kelimeler: Akciğer, İzoniazid, Krisin, Oksidatif Stres.

To cite this article: Kücükler S. Özdemir S. Comakh S. Kandemir F.M. Effects of Chrysin Against Isoniazid-Induced Lung Injury in Rats. Kocatepe Vet J. (2020) 13(2):161-171 


\section{GİRİ̧̧}

Mycobacterium tuberculosis'in neden olduğu bir hastalık olan tüberküloz (TB), insanlık tarafindan bilinen en eski ve en ölümcül hastalıklardan biridir (Organization 2013). Anti-tüberküloz kemoterapisinin ortaya çımasıyla, hastalı̆̆ın tedavisinde ciddi bir iyileşme olmuştur. Anti-tüberküloz ilaçlar arasında bulunan izoniazid (IZN), aktif tüberkülozun tedavisi ve profilaksisi için kullanılan ilaçtır (Basheer ve ark. 2017, Chowdhury ve ark. 2006, Eftekhari ve ark. 2018). Aktif tüberkülozun tedavisinde yaygin olarak kullanilan IZZN'nin, gastrointestinal bozukluk, hepatotoksisite, periferik nörotoksisite, merkezi sinir sisteminde başta olmak üzere çeşitli yan etkileri olduğu için kullanımı sınırlanmaktadır (Ahadpour ve ark. 2016). Yapılan araştırmalar, oksidatif stresin IZN kaynaklı sitototoksisiteden sorumlu mekanizmalardan biri olduğunu ileri sürmektedir (Cicek ve ark. 2005). Başarılı bir anti-tüberküloz ilacı ile tedaviden sonra klinik olarak iyileşme gözlenmesine rağmen, antitüberküloz ilaçların yüksek düzeyde oksidatif stresin devamına neden oldukları belirtilmiştir (Plit ve ark. 1998).

Yeterli düzeyde reaktif oksijen türü (ROS) normal hücresel fonksiyonu korumak için sinyal molekülleri olarak işlev görürken, pro-oksidan ve antioksidan sistemler arasındaki denge bozuklukları nedeniyle aşırı ROS üretimi çoğu dokuda oksidatif hasara neden olur (Choi 2019). Oksidatif hasar sonucu artan ROS, DNA oksidasyonu, lipit peroksidasyonu ve endotelyal hücre hasarına neden olur ve bu işleyiş çoğu dokuda görülen hasarın ana mekanizması olarak bilinmektedir (Zhang ve ark. 2018).

Nükleer faktör kappa B (NF- $x \mathrm{~B})$, inflamasyon ve çeşitli otoimmün hastalıklarda yer alan genlerin indüklenebilir ekspresyonunun önemli bir düzenleyicisi olarak hizmet eden bir redoks transkripsiyon faktörüdür (Caglayan ve ark. 2019). Bilinen bir transkripsiyon faktörü olarak nükleer faktör eritroid-2 ile ilişkili faktör 2 (Nrf-2), antioksidan ve detoksifikasyon enzimlerinin ekspresyonunu uyarabilen ve oksidatif stresin hücresel yanıtını sağlayan önemli bir transkripsiyon faktörüdür (Çelik ve ark. 2020).

Nrf-2, oksidatif stresin düzenlenmesinde önemli bir rol oynayan ana redoks algilama transkripsiyon faktörü olduğu iyi bilinmektedir. Normal olarak, oksidatif stres uyarımı altında, Nrf-2 aktive edilir, Keap1- Nrf-2 kompleksinden salınır ve sitoplazmadan çekirdeğe aktarılır. Ayrıca Heme oksijenaz-1 (HO-1) dahil olmak üzere çeşitli antioksidatif genlerin transkripsiyonunu başlatır. Bununla birlikte, birçok çalışma, HO-1 indüksiyonunun, Nrf-2 sinyallemesinin in vitro ve in vivo aktivasyonu ile LPS kaynaklı enflamasyon tepkilerini bloke ettiğini göstermiştir (Chepelev ve ark. 2013, Park ve ark. 2013, Zhang ve ark. 2017).

Flavonoidler, anti-inflamatuar, antibakteriyel, antialerjik, antiapoptotik, antitrombotik ve vazodilatör dahil biyolojik ve farmakolojik özellikler sergileyen bitki kaynaklı doğal fenolik bileşiklerdir (Kandemir ve ark. 2020). Krisin (5,7 - dihidroksiflavon) doğal bir flavonoiddir. Birçok bitki özünde, balda, propoliste ve çeşitli çiçeklerin uçucu yağlarında bol miktarda bulunan KRS'nin varolan birçok yararlı etkileri bilinmektedir. KRS yararlı etkilerinden dolayı son yillarda yaygin olarak kullanılmaktadır (Eldutar ve ark. 2017, Kandemir ve ark. 2017, Mehri ve ark. 2014, Temel ve ark. 2020).

Sunulan çalışmada, İZN'nin ratların akciğerleri üzerindeki etkisini ve bu etkilerin KRS ile birlikte tedavi edilerek düzeltilip düzeltilemeyeceğinin değerlendirilmesi amaçlanmıştır. Bu amaca ulaşmak için, ratlara oral olarak gavaj yoluyla 7 gün boyunca IZN ve / veya KRS verildi, ardından akciğer dokularında antioksidan aktivite, patolojik değişiklikler ile farklı parametreler biyokimyasal, histopatolojik ve gen ekspresyonu yöntemleri ile incelenmiştir.

\section{MATERYAL ve METOT}

\section{Kullanılan Deney Hayvanları}

Çalışmada ağırlıkları 220-250 gr, yaşları 10-12 haftalık olan erkek Sprague Dawley cinsi rat kullanıldı. Kafeslerde bulunan hayvanlar, $24 \pm 1^{\circ} \mathrm{C}$ sabit sicaklikta ve on ikişer (12 h) saatlik karanlı/aydınlık siklüsü sağlanarak kontrollü bir odada tutuldu. Çalışmaya başlamadan önce ratların 7 gün süreyle ortama adaptasyon sağlamaları için herhangi bir uygulama yapilmadan beklendi. Sprague Dawley ratlara yem (pelet) ve su ad libitum olarak verildi. Bu çalışma Atatürk Üniversitesi Rektörlügü Hayvan Deneyleri Yerel Etik Kurulu Başkanlığı tarafindan onaylandı (Karar No: 118/2019).

\section{Çalışmada Kullanılan İlaçlar}

İzoniazid (İZN): Çalışmada kullanılan İZN'nin (I.N.H. 300 mg Tablet, Koçak Farma) doz seçiminde literatür verisinden yararlanıldı (Ruan ve ark. 2018).

Krisin (KRS): Çalışmada kullanılan antioksidan KRS Sigma-Aldrich firmasindan temin edildi. Çalışmamızda kullanmış olduğumuz doz literatürde belirtildiği şekilde uygulandı (Eldutar ve ark. 2017).

\section{Deneysel Uygulamalar}

Deneyde kullanilacak ratlar, her bir grupta yedi hayvan olacak şekilde beş gruba ayrildı. Deney tasarımı aşağıdaki gibi bir kontrol ve dört deney grubunu içermiştir; 
1- Kontrol Grubu: 7 gün oral serum fizyolojik verildi. 2- İZN Grubu: 7 gün $400 \mathrm{mg} / \mathrm{kg} /$ gün İZN oral olarak verildi.

3- KRS 50: 7 gün $50 \mathrm{mg} / \mathrm{kg}$ vücut ağırlı̆̆1/gün KRS oral olarak verildi.

4- İZN + KRS 25 Grubu: 25 mg/kg/gün KRS (oral) uygulamasindan $30 \mathrm{dk}$. sonra IZN $400 \mathrm{mg} / \mathrm{kg}$ dozunda oral verildi ve uygulama 7 gün yapıld1.

5- İZN + KRS 50 Grubu: 50 mg/kg/gün KRS (oral) uygulamasindan $30 \mathrm{dk}$ sonra IZN $400 \mathrm{mg} / \mathrm{kg}$ dozunda oral verildi ve uygulama 7 gün yapıld1.

\section{Numunelerin alınması}

Yapılan son uygulamadan 24 saat sonra (8.gün) ratlar hafif sevofloran anestezisi altında dekapite edildi. Ratlardan akciğer dokuları alınarak bir kısmı gen ekspresyonu ve biyokimyasal analizler yapilincaya kadar $-80^{\circ} \mathrm{C}$ 'de muhafaza edilirken, diğer bir kısım ise patolojik incelemeler amaciyla $10 \%$ 'luk tamponlu formaldehit solüsyonda tespit edildi. Biyokimyasal olarak ve gen ekspresyonu için analizlere başlamadan önce akciğer dokularından gerekli olan miktarlarda tartıld1. Yapilacak analizlerin metodların da belirtilen tamponlarla belirtilen oranda sulandirılarak TissueLyser II (Qiagen) ile homojenizasyon işlemi yapild1.

\section{Biyokimyasal Analizler}

Akciğer dokuları homojenatlarında LPO (Lipid peroksidasyon) ürünü olan MDA ölçümü Placer ve ark.'nın (Placer ve ark. 1966), GSH düzeyleri Sedlak ve Lindsay'in (Sedlak and Lindsay 1968), GPx aktivitesinin ölçümü Matkovics'in (Matkovics 1988), SOD aktivitesinin ölçümü Sun ve ark.'nın (Sun ve ark. 1988), KAT aktivitesi Aebi'nin metoduna göre spektrofotometrik olarak ölçüldü (Aebi 1974). Homojenattaki protein konsantrasyonu, Lowry ve ark.'nın metoduna göre belirlendi (Lowry ve ark. 1951).

\section{Histopatolojik İnceleme}

Akciğerlere ait histopatolojik incelemeler için önceki çalışmalarımızdaki prosedürler izlendi (Cengiz ve ark. 2017, Comakli ve ark. 2019, Çomakli ve ark. 2020). Tespit edilen akciğer dokuları formaldehitin uzaklaştırılması amacıyla akan su ile muamele edildi. Dereceli alkol ve ksilol solüsyonlarında dehidrasyon ve şeffaflandırma işlemi gerçekleştirilen akciğer doku örnekleri parafin bloklara gömüldü, daha sonra $5 \mu$ kalınlıkta kesitler normal ve polilizinli lamlara alındı. Normal lam üzerine alınan dokular hematoksileneozin (HE) ile boyandi. Akciğerlerde gözlenen histopatolojik değişiklikler 1ş1k mikroskobu altında fotoğraflandı (Zeiss, AX10 Scope A1, Almanya).

\section{İmmunhistokimyasal boyama}

Polilizinli lamlara alınan kesitler ksilol içinde iki kez (5 dk.) parafinden arındırıldı, ardından dereceli alkol içinde dehidre edildi ve son olarak distile suda $10 \mathrm{dk}$. bekletilerek rehidre edildi. Kesitler spesifik olmayan boyamay1 en aza indirmek amaciyla $10 \mathrm{dk}$. 3\%'lük hidrojen peroksit solüsyonunda bekletildi ve fosfat tamponlu salin (PBS) ile 2 kez yikandi. Antijen retrieval için kesitler, $10 \mathrm{mM}$ sitrat tamponu ( $\mathrm{pH}$ 6.0) içerisinde 10 dakika kaynatıldı ve PBS ile yıkandı. 10 dakika boyunca protein blok solüsyonu uygulandiktan sonra kesitler, anti- NF- $x$ B (p50) (1: 200, Santa Cruz Biotechnology, Katalog No: sc-8414) ile 30 dk. inkübe edildi. Kesitler üç ayrı PBS yıkaması ile durulandı ve daha sonra biyotinlenmiş sekonder antikor (Ultra Vision Large Volume Detection System; TP-125-HL; Lab Vision, Thermo) kullanılarak 10 dakika süreyle inkübe edildi. Son olarak, kesitler belli bir süre DAB ile muamele edildi ve Mayer hematoksilin ile zit boyand. Dehidrasyondan sonra, kesitler ksilen içine alındı ve entellan ile kaplandı. Işı mikroskobu altında immunpozitiflikler yoğunluğa göre yok: 0, zayıf: 1, orta: 2, yoğun boyanma: 3 şeklinde incelendi (Zeiss, AX10 Scope A1, Almanya).

\section{Total RNA İzolasyonu}

Deneysel gruplardaki ratlardan elde edilen akciğer dokularindan Trizol kullanilarak total RNA izolasyonu yapıldı. Bu işlem kitin prosedürüne uygun olarak yapildı. Total RNA izolasyonunda sonra RNA konsantrasyonu NanoDrop ile ölçüldü. Total RNA kalitesini kontrol etmek amaciyla RNA'lar \%1.5'lik agaroz jel de 1XTBE solusyonu içerisinde 80 voltta bir saat yürütüldü ve jel görüntüleme sistemi ile görüntülenerek RNA kalitesi belirlendi.

\section{Primer Dizayn}

Apoptozis ile ilişkili olan Nrf-2 ve HO-1 genlerine ait ekspresyon seviyelerinin Real Time PCR ile ölçülebilmesi için gerekli primer dizileri http://bioinfo.ut.ee/primer3-0.4.0/ ilgili linkindeki Primer Design-3 programı kullanılarak tasarland.

\section{DNaz I uygulaması ve cDNA çevrimi}

İzole edilen RNA örneklerinde DNA kontaminasyonuna karşı DNaz I (Thermo Scientific) kullanıld1. Dnaz I uygulaması kitte verilen protokole uygun olarak yapild1. Daha sonra bu RNA'lardan 2-5 $\mu \mathrm{g}$ alind1 ve miScript Reverse Transcription Kiti (Qiagen) verilen protokole uygun şekilde kullanılarak cDNA sentezlendi. Elde edilen cDNA'nın saflığ1 ve miktar1 spektrofotometrede yap1lan 260-280 nm absorbans ölçümleri ile belirlendi ve cDNA'lar aynı oranlarda sulandirild. Daha sonra Real Time PCR çalışmalarında kullanılmak üzere $-20^{\circ} \mathrm{C}$ de muhafaza edildi.

\section{Real time PCR}

Nrf-2 ve HO-1 genlerinin mRNA transkript seviyelerini ölçmek amaciyla Qiagen Rotor Gene HRM marka cihaz kullanılarak qRT-PCR yapıldı. Internal kontrol olarak GAPDH geni kullanıldı. Real 
time PCR deneylerinde oluşturulan master mix içeriği; Syber Green 2X Rox Dye Master mix (Qiagen), genler için tasarlanmış forward ve reverse primerler, template olarak cDNA'lar ve nükleaz free su içermekteydi. Master mixler hazırlandıktan sonra örnekler Real Time cihazında analiz edildi ve elde edilen $\mathrm{Ct}$ değerleri $2-\Delta \Delta \mathrm{CT}$ metoduna uygun olarak hesaplanarak ilgili genlerin ekspresyon seviyeleri belirlendi (Livak and Schmittgen 2001). Genlerin reaksiyon koşulları ve primer dizileri Çizelge 1'de gösterilmiştir.

\section{İstatistiksel Analiz}

Çalışmadan elde edilen tüm verilerin istatistiksel analizi SPSS 20.0 yazılımı kullanılarak yapıldı. Biyokimyasal veriler tek yönlü varyans analizi (ANOVA) testi ile belirlenmiş olup çoklu karşılaştırmalar için Tukey's HSD testi uygulandı. $\mathrm{p}<0.05$ seviyesindeki sonuçlar anlamlı kabul edildi. İmmunhistokimyasal verilerin analizi için parametrik olmayan Kruskal Wallis testi ve Mann-Whitney U testi kullanıldi. Ayrica genlere ait ekspresyon seviyeleri analiz etmede GrapPad 7.2 (California, USA) programı kullanıldı.

\section{BULGULAR}

\section{Biyokimyasal Değerlendirme}

Ratlara uygulanan IZN, kontrol grubu ile karşılaştırıldığında akciğer dokusundaki MDA seviyesinde artışa neden olduğu belirlendi (Şekil 1A). Kontrol grubu ile KRS gruplar1 arasinda istatistiksel olarak anlamlı fark olmadığı $(\mathrm{p}>0.05)$ tespit edildi. IZN ile uygulanan KRS'nin kombine dozlarının uygulaması ile artan bu MDA düzeylerinde önemli derecede azalmayı sağladığ belirlendi $(\mathrm{p}<0.05)$. Benzer şekilde IZN uygulamas1, kontrol ve sadece KRS uygulanan gruba kıyasla anlamlı şekilde akciğer dokusundaki GSH düzeylerini azalttığ1 $(\mathrm{p}<0.05)$ gözlenirken IZZN + KRS $50 \quad(50 \mathrm{mg} / \mathrm{kg} \quad \mathrm{doz})$ uygulamasının, GSH düzeyini IZZN uygulanan gruba kıyasla anlamlı şekilde artırdığı $(\mathrm{p}<0.05)$ tespit edildi (Şekil 1B).

Akciğer dokusunda SOD aktiviteleri incelendiğinde; (Şekil 2A) Kontrol ve KRS gruplarına göre IZZN grubunda aktivitenin azaldığı( $(\mathrm{p}<0.05)$, İN ile birlikte uygulanan KRS ile azalan SOD aktivitesinin arttığ $(p<0.05)$ tespit edildi. Akciğer dokuları KAT aktiviteleri incelendiğinde (Şekil 2B) kontrol ve KRS gruplarında KAT aktiviteleri arasinda istatistiksel olarak anlamlı fark olmadığ $(\mathrm{p}>0.05)$, IZN uygulanan grupta ise kontrol ve KRS gruplarına göre aktivitede önemli derecede azalma $(\mathrm{p}<0.05)$ olduğu gözlendi. IZN grubu ile IZN + KRS 25 grubu arasinda istatistiksel fark bulunamazken ( $p>0.05$ ), KRS'nin 50 $\mathrm{mg} / \mathrm{kg}^{\prime} \mathrm{llk}$ dozunun IZN grubundaki aktiviteyi yükselttiği tespit edildi $(\mathrm{p}<0.05)$.
Şekil 2C'de verilen GPx enzim aktiviteleri incelendiğinde; Kontrol ile KRS gruplarına göre antioksidan enzim aktivitesinde önemli derecede azalma $(\mathrm{p}<0.05)$ olduğu, IZN ile kombine olarak verilen KRS'in 25 ve $50 \mathrm{mg} / \mathrm{kg}^{\prime} l \mathrm{lk}$ dozlarının GPx aktivitesini artırdığ1 $(\mathrm{p}<0.05)$ IZN ile birlikte verilen KRS'in $25 \mathrm{mg} / \mathrm{kg}$ ve $50 \mathrm{mg} / \mathrm{kg}^{\prime} \mathrm{llk}$ doz uygulanan grupları arasinda istatistiksel olarak anlamlı fark olmadığı ( $(\mathrm{p}>0.05)$ gözlendi.

\section{Histopatolojik değerlendirme}

Kontrol grubundaki ratların akciğerleri, histopatolojik olarak hafif alveoler hiperemi dışında normal histolojik yapiya sahipti (Şekil 3A). KRS uygulanan ratların akciğerlerinde de kontrol grubuna benzer bulgular gözlendi (Şekil 3B). IZNN uygulanan gruptaki ratların akciğerlerinde alveoller arası dokunun hücresel infiltrasyona bağlı artış, peribronşiyal lenfoid dokunun hiperplazi, alveollerde hafif düzeyde hiperemi ve amfizem bulguları gözlendi (Şekil 3C). IZN ile birlikte KRS uygulamalarının akciğerdeki histopatolojik bulguları hafiflettiği özellikle KRS 50 $\mathrm{mg} / \mathrm{kg}$ uygulanan dozunun etkili olduğu saptanmıştır. IZN ile KRS $25 \mathrm{mg} / \mathrm{kg}$ doz uygulanan ratların akciğerlerinde alveoller arası hücresel infiltrasyona bağlı kalınlaşmanın ve peribronşiyal lenfoid dokudaki hiperplazinin IZN uygulanan gruba göre nispeten hafiflediği gözlendi (Şekil 3D). IZN ile KRS 50 $\mathrm{mg} / \mathrm{kg}$ doz uygulanan ratların akciğerlerinde ise alveollerin normal histolojik yapısını çoğunlukla koruduğu bazı bölgelerde alveoller arası hücresel infiltrasyonun arttığı belirlendi (Şekil 3E).

\section{İmmunhistokimyasal inceleme}

$\mathrm{NF}-x \mathrm{~B}$ için pozitif hücreler immunhistokimyasal boyamada kahverengi şeklinde gözlenmektedir. Kontrol ve sadece krisin uygulanan gruptaki ratların akciğerlerinde $\mathrm{NF}-x \mathrm{~B}$ immunpozitifliğine rastlanmadı (Şekil 4A, 4B). İZN uygulanan gruptaki ratların akciğer kesitlerinde yoğun $\mathrm{NF}-x \mathrm{~B}$ immunpozitifliği gözlendi ( $\mathrm{p}<0.05$, Çizelge 2, Şekil 4C). IZZN ile birlikte uygulanan KRS $25 \mathrm{mg} / \mathrm{kg}$ (Şekil 4D) ve $50 \mathrm{mg} / \mathrm{kg}$ (Şekil 4E) dozlarının, artan NF- $x \mathrm{~B}$ seviyelerini önemli düzeyde azalttığı belirlenmiştir ( $\mathrm{p}<0.05$, Çizelge 2$)$.

\section{Nrf-2 ve HO-1 genlerine ait mRNA transkript seviyeleri}

Çalışma sonucunda elde edilen qRT-PCR verileri incelendiğinde, kontrol ve KRS gruplarında Nrf-2 ve HO-1'in ekspresyon profilinde herhangi bir değişimin olmadığ $\quad(\mathrm{p}>0.05) \quad$ ancak sadece IZN uygulanan ratların akciğer dokularında $\mathrm{Nrf}-2$ ve HO-1'in mRNA transkript seviyesinin arttığ1 gözlemlendi $(\mathrm{p}<0.01)$. Bunun yanında özellikle İZN + KRS 50 grubunda bu genlere ait ekspresyon seviyesinin sadece İZN uygulanan gruba göre önemli derecede azaldığ1 belirlendi $(\mathrm{p}<0.05)$ (Şekil 5A ve Şekil 5B). 
A

MDA

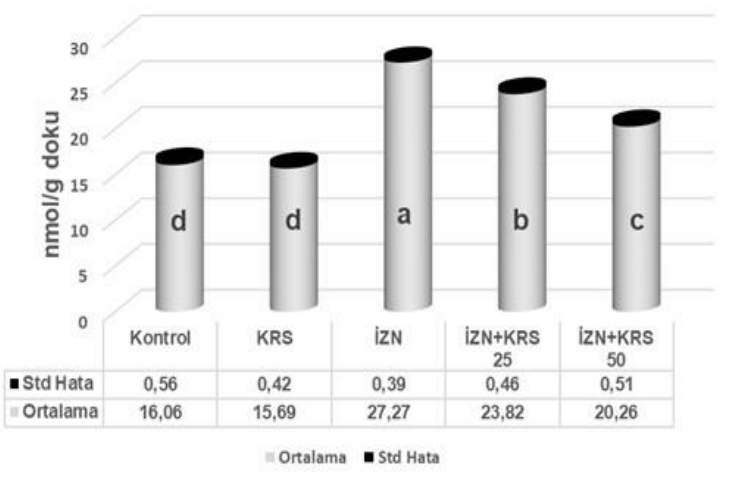

B

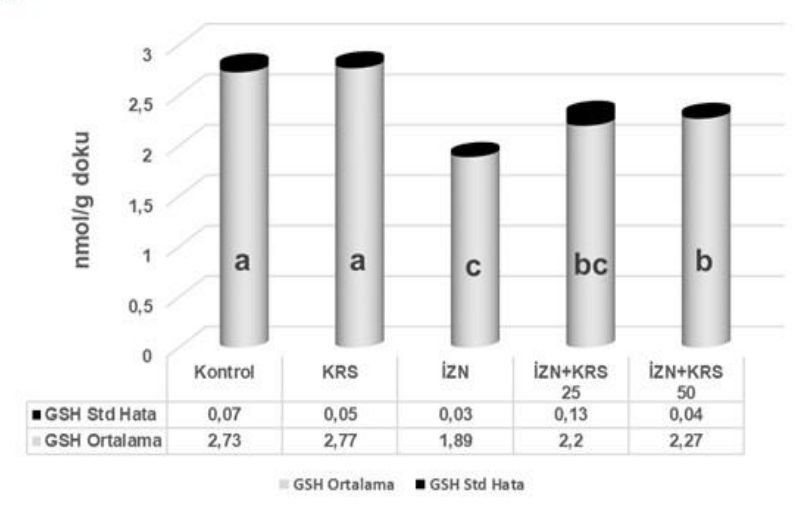

Şekil 1. Akciğer dokusu MDA (A) ve GSH (B) düzeyleri. Farklı harfler (a, b, c, d), gruplar arası farklılı̆ı ifade eder $(\mathrm{p}<0.05)$.

Figure 1. Lung tissue MDA (A) and GSH (B) levels. Different letters (a, b, c, d) express the difference between the groups $(\mathrm{p}<0.05)$.

A

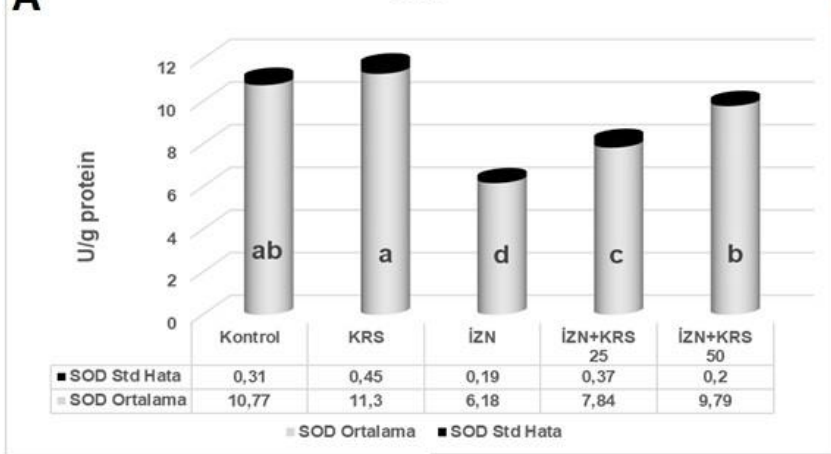

B

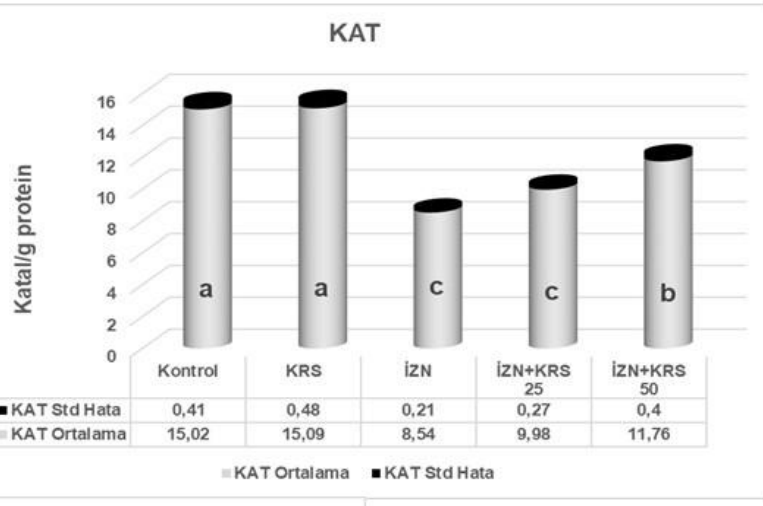

C GPX

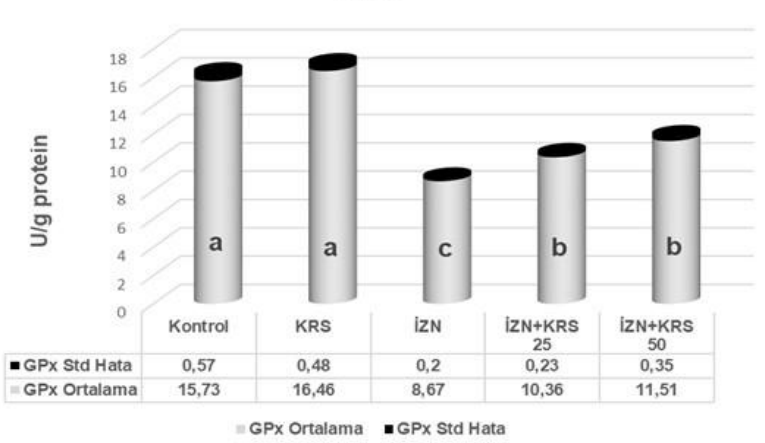

Şekil 2. Akciğer dokusu SOD (A), KAT (B) ve GPx (C) aktiviteleri. Farklı harfler (a, b, c, d), gruplar arası farkllilı̆ ifade eder $(\mathrm{p}<0.05)$.

Figure 2. Lung tissue SOD (A), CAT (B) and GPx (C) activities. Different letters (a, b, c, d) express the difference between the groups $(\mathrm{p}<0.05)$. 


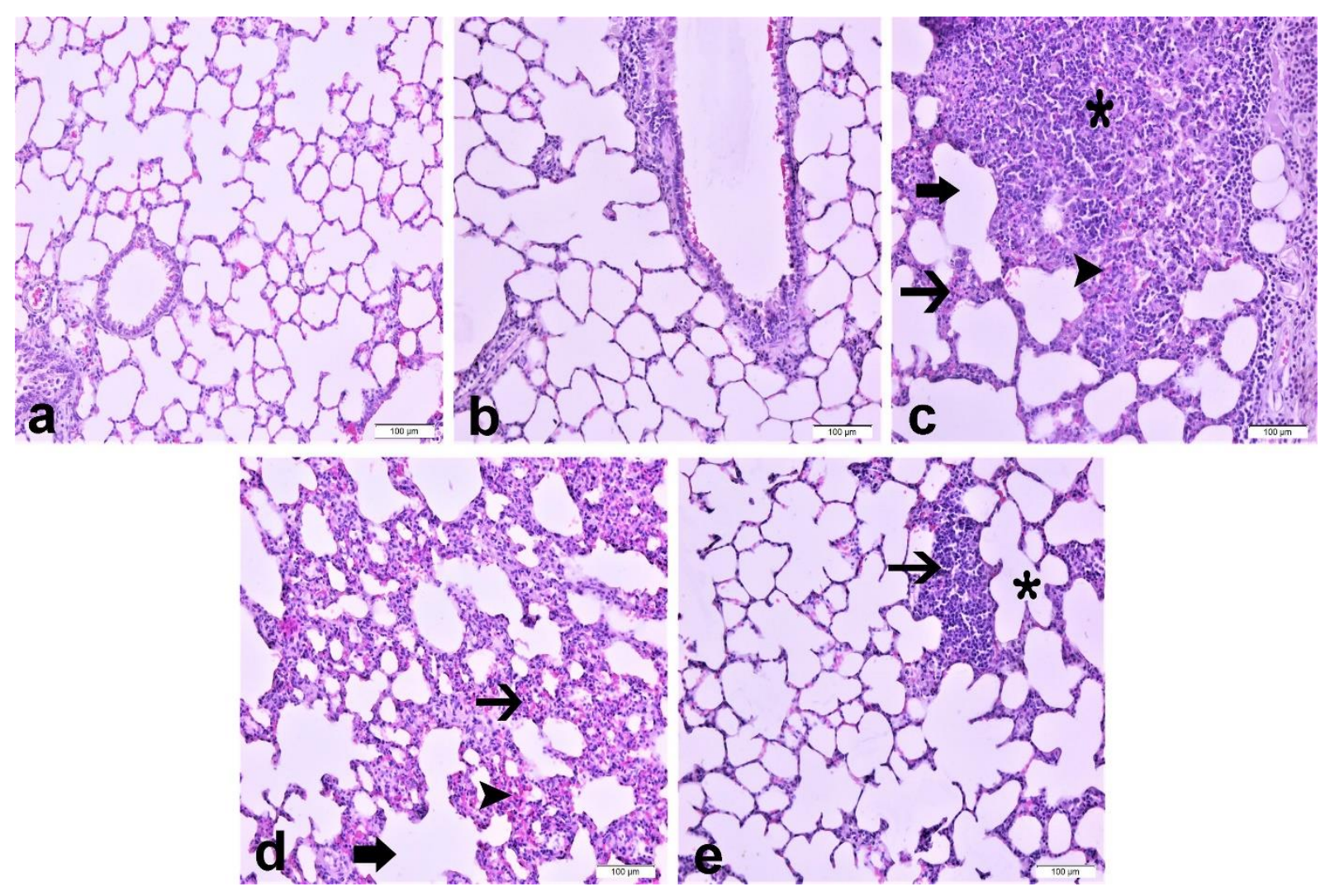

Şekil 3: IZZN ve KRS uygulamalarından sonra rat akciğerlerinde histopatolojik değişiklikler. Hematoksilen ve eozin ile boyanmış akciğer kesitlerinin temsili görüntüleri. Farklı deney gruplarındaki yetişkin sıçanların akciğerlerinde histopatoloji tablosunu gösteren Hematoksilen ve eozin boyama (H\&E, 20X). (a-b) Normal alveol yapilar1 ve hafif hiperemi ile gözlenen kontrol ve KRS gruplar1; (c) IZN uygulanan grup, Peribronşiyoler lenfoid dokuda hiperplazi (yıldız), alveol duvarlarında hafif hiperemi (okbaşı), alveoller arası septumda yangısal hücre infiltrasyonuna bağlı kalınlaşma (ince ok) ve amfizem (kalın ok); (d) İZN+KRS (25 mg/kg) uygulanan grup, alveoller arası septumda yangısal hücre infiltrasyonuna bağlı kalınlaşma (ince ok), alveol duvarlarında hafif hiperemi (okbaşı) ve amfizem (kalın ok); (e) IZN+KRS (50 mg/kg) uygulanan grup, amfizemli (yıldız) ve normal alveol yapıları, alveoller arası septumda yangısal hücre infiltrasyonuna bağlı kalınlaşma (ince ok).

Figure 3: Histopathological changes in rat lungs after isoniazid and chyrsin administrations. Representative images of lung sections stained with hematoxylin and eosin. Hematoxylin and eosin staining (H\&E, 20X) showing the histopathology table in the lungs of adult rats in different experimental groups. a-b) Control and $\mathrm{CH}$ groups observed with normal alveolar structures and mild hyperemia; (c) INH-treated group, hyperplasia in the peribronchiolar lymphoid tissue (star), mild hyperemia in the alveolar walls (arrowheadl), thickening due to inflammatory cell infiltration in the septum between the alveoli (thin arrow) and emphysema (thick arrow); (d) $\mathrm{INH}+\mathrm{CH}(25 \mathrm{mg} / \mathrm{kg})$ treated group, thickening (thin arrow) due to inflammatory cell infiltration in the septum between the alveoli, mild hyperemia (arrowhead) and emphysema (thick arrow); (e) INH+CH (50 mg/kg) group, emphysema (star) and normal alveolar structures, thickening due to inflammatory cell infiltration in the septum between the alveoli (thin arrow). 

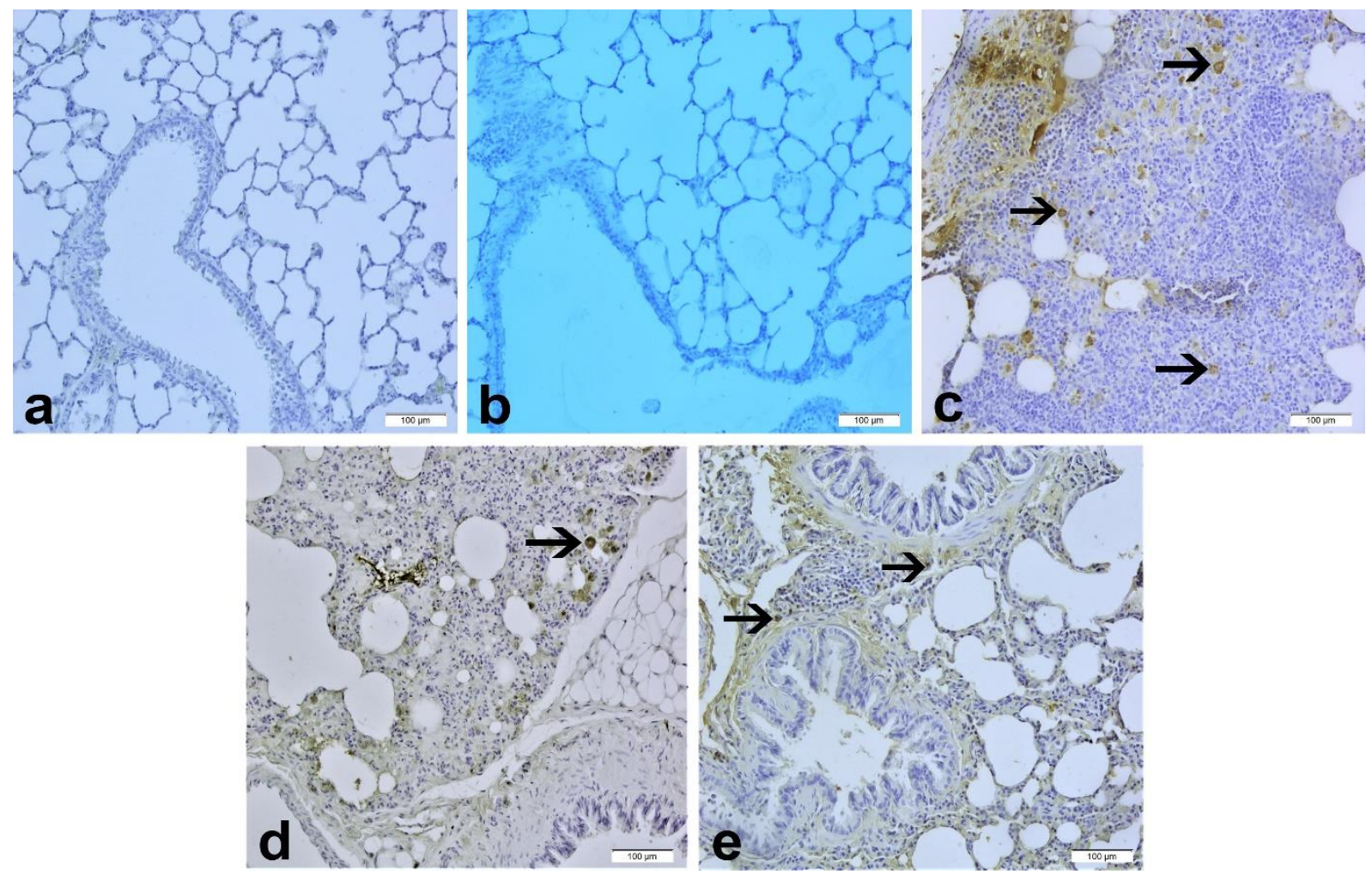

Şekil 4: Akciğer dokusunda NF-xB'nin ekspresyonu gösteren immunhistokimyasal boyama (IHC, 20 X). (a) Kontrol grubunu gösteren fotomikrograf; (b) KRS ile muamele edilmiş grup; (c) IZZN uygulanan grup, şiddetli yang1 şekillenen akciğer dokusunda histiyositlerin sitoplazmasında yoğun NF- $x$ B immunopozitifliği (oklar); (d) IZZN+KRS $(25 \mathrm{mg} / \mathrm{kg}$ ) uygulanan grup, alveoller arasındaki septumda histiyositlerin sitoplazmasında hafif ve orta düzeyde NFxB immunopozitifliği (ok); (e) İZN+KRS (50 mg/kg) uygulanan grup, bronşiyolün çevresindeki yangı hücrelerinin sitoplazmasinda hafif $\mathrm{NF}-x \mathrm{~B}$ immunpozitifliği (oklar).

Figure 4: Immunohistochemical staining showing the expression of $\mathrm{NF}-x \mathrm{~B}$ in lung tissue (IHC, $20 \mathrm{X}$ ). (a) Photomicrograph showing the control group; (b) $\mathrm{CH}$-treated group; (c) INH-treated group, intense $\mathrm{NF}-x \mathrm{~B}$ immunopositivity in the cytoplasm of histiocytes in the lung tissue with severe inflammation (arrows); (d) $\mathrm{INH}+\mathrm{CH}$ $(25 \mathrm{mg} / \mathrm{kg}$ ) group, mild and moderate NF-xB immunopositivity in the cytoplasm of histiocytes in the septum between the alveoli (arrow); (e) INH+CH $(50 \mathrm{mg} / \mathrm{kg}$ ) treated group, mild NF- $x \mathrm{~B}$ immunopositivity (arrows) in the cytoplasm of inflammatory cells around the bronchiole.
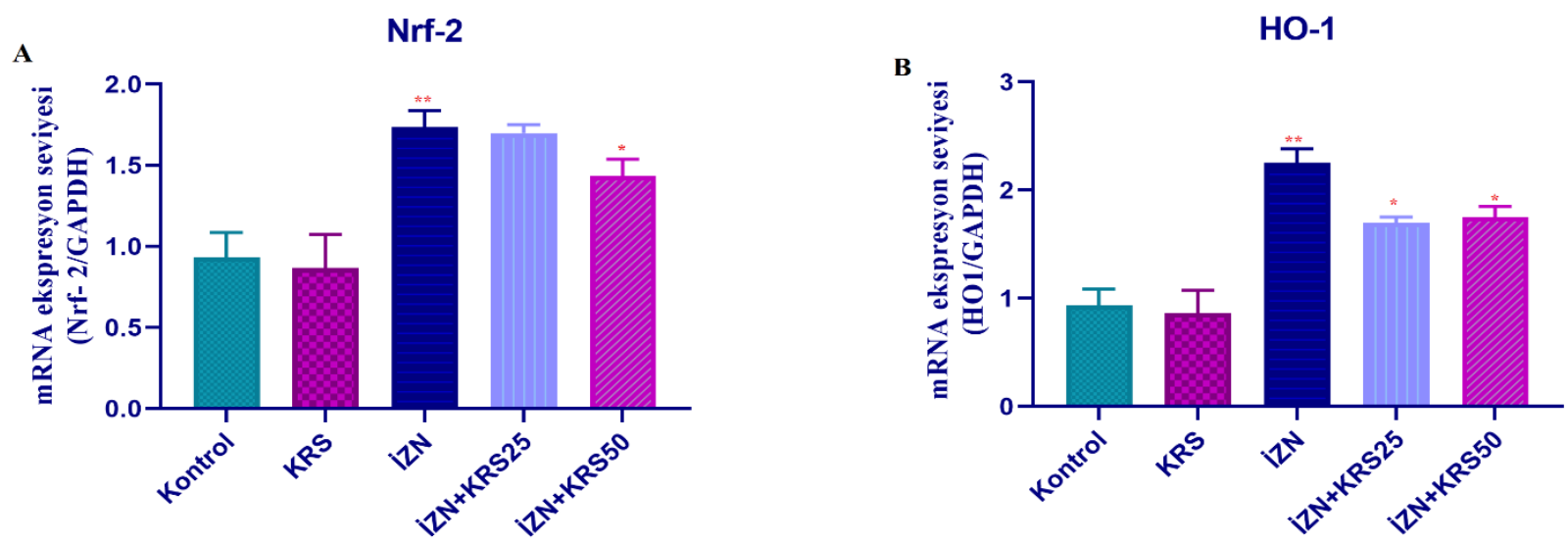

Şekil 5. Deneysel gruplardaki ratların akciğer dokularında Nrf-2 ve HO-1 genlerine ait mRNA transkript seviyeleri. Değerler 3 bağımsız örneklemin ortalama \pm SD' sini temsil eder; Hata çubukları standart sapmayı gösterir. İstatistiksel anlamlılık (* $\mathrm{p}<0.05,{ }^{* *} \mathrm{p}<0.01$ ve $* * * \mathrm{p}<0.001$ ), tek yönlü ANOVA ile analiz edildi. A) Nrf-2 geninin göreceli mRNA ekspresyon seviyelerini temsil eder. B) HO-1 geninin göreceli mRNA ekspresyon seviyelerini temsil eder.

Figure 5. The mRNA transcript levels of Nrf-2 and HO-1 genes in the lung tissues of the rats in the experimental groups. Values represent the mean \pm SD of 3 independent samples; Error bars indicate standard deviation. Statistical significance $(* \mathrm{p}<0.05$, ** $\mathrm{p}<0.01$ and $* * * \mathrm{p}<0.001)$ were analyzed by one-way ANOVA. A) Represents relative mRNA expression levels of the Nrf-2 gene. B) Represents the relative mRNA expression levels of the HO-1 gene. 
Tablo 1. GAPDH, Nrf-2 ve HO-1 genlerine ait qRT-PCR Primer Dizileri

Table 1. qRT-PCR Primer Sequences of GAPDH, Nrf-2 and HO-1 genes

\begin{tabular}{|c|c|c|c|}
\hline Primer Ad1 & $\left(5^{\prime}-3^{\prime}\right)$ & $\begin{array}{l}\text { Bağlanma } \\
\left({ }^{\circ} \mathrm{C}\right)\end{array}$ & Reaksiyon koşulları \\
\hline GAPDH & $\begin{array}{l}\text { F: AGTGCCAGCCTCGTCTCATA } \\
\text { R: GATGGTGATGGGTTTCCCGT }\end{array}$ & 56 & $\begin{array}{l}94^{\circ} \mathrm{C} 15 \mathrm{~s} / 56^{\circ} \mathrm{C} 30 \mathrm{~s} / 72^{\circ} \mathrm{C} 30 \mathrm{~s}(40 \\
\text { cycles) }\end{array}$ \\
\hline$N r f-2$ & $\begin{array}{l}\text { F: TTTGTAGATGACCATGAGTCGC } \\
\text { R: TCCTGCCAAACTTGCTCCAT }\end{array}$ & 56 & $\begin{array}{l}94^{\circ} \mathrm{C} 15 \mathrm{~s} / 56^{\circ} \mathrm{C} 30 \mathrm{~s} / 72^{\circ} \mathrm{C} 30 \mathrm{~s}(40 \\
\text { cycles) }\end{array}$ \\
\hline HO-1 & $\begin{array}{l}\text { F: CGACAGCATGTCCCAGGATT } \\
\text { R: TCACCAGCTTAAAGCCTTCCC }\end{array}$ & 56 & $\begin{array}{l}94^{\circ} \mathrm{C} 15 \mathrm{~s} / 56^{\circ} \mathrm{C} 30 \mathrm{~s} / 72^{\circ} \mathrm{C} 30 \mathrm{~s}(40 \\
\text { cycles })\end{array}$ \\
\hline
\end{tabular}

Tablo 2. IZN uygulamasına bağı değişen NF- $x$ B immunpozitifliği üzerine KRS antioksidanının etkisi

Table 2. Effect of $\mathrm{CH}$ antioxidant on $\mathrm{NF}-x \mathrm{~B}$ immunopositivity varying due to INH treatment

\begin{tabular}{lc}
\hline Gruplar & Ortalama \pm Std. Hata \\
\hline Kontrol & $0,28 \pm 0,18^{\mathrm{a}}$ \\
KRS & $0,14 \pm 0,14^{\mathrm{a}}$ \\
$\mathrm{IZN}$ & $2,85 \pm 0,14^{\mathrm{b}}$ \\
$\mathrm{IZN}+\mathrm{KRS} 25 \mathrm{mg} / \mathrm{kg}$ & $1,85 \pm 0,26^{\mathrm{c}}$ \\
$\mathrm{IZN}+\mathrm{KRS} 50 \mathrm{mg} / \mathrm{kg}$ & $1,57 \pm 0,20^{\mathrm{c}}$ \\
\hline
\end{tabular}

Değerler ortalama \pm Standart hata, $\mathrm{p}<0.05$, farklı harfler (abc) gruplar arası farkllık olarak ifade edilir.

\section{TARTIŞMA}

Bu çalışmada, KRS’nin Sprague Dawley cinsi ratlarda IZN kaynaklı akciğer hasarına karşı koruyucu etkilerini inceledik. Anti-tüberküloz tedavisi, hepatotoksisite, nefrotoksisite ve deri döküntüsü dahil olmak üzere çeşitli ilaca bağlı yan etkilere neden olabilir (Ohta ve Nagase 2012, Suzuki ve ark. 1992). Bu ilaçlardan IZN'nin neden olduğu pnömonitis gibi interstisyel akciğer hastalığ1 hakkında bazı vaka raporlar1 bildirilmiştir (Kunichika ve ark. 2002, Nishizawa ve ark. 2004). Yapilan birçok çalışmada yine IZZN'nin ilaç kaynaklı akciğerlerde pnömonitis oluşmasının en yaygın nedeni olduğu öne sürülmüştür (Suzuki ve ark. 1992, Nishizawa ve ark. 2004, Endo ve ark. 1998). IZN ile indüklenen interstisyel pnömoni tanısı esas olarak ilaç kaynaklı interstisyel pnömoni ile uyumlu ilaç öyküsü ve akciğer patolojisine dayanır (Migita ve ark. 2012). Sunulan çalışmada IZN uygulanan gruptaki ratların akciğer patolojisinde akciğerlerin alveol lümenlerinin boş olması, alveoller arası dokuda hücresel infiltrasyona bağlı artış ve peribronşiyal lenfoid dokudaki hiperplazi gibi bulguların gözlenmesi IZN'nin intersitisyel pnömoni oluşturduğu ve literatür veriyle uyumlu olduğunu göstermiştir. Yine çalışmamızda antioksidan olarak kullandığımız KRS'nin farklı maddelerle oluşturulan akciğer hasarlarına karşı koruyucu özellik gösterdiği bildirilmiştir (Kilic ve ark. 2014, Yang ve ark. 2018). Sunulan çalışmada İZN kaynaklı akciğer hasarına karşı KRS uygulamasının oksidatif hasarı ve enflamatuar etkiyi azaltarak etkili olduğu gözlenmiş ve literatür veriyle uyumluluğu belirlenmiştir.
Sunulan çalışmada, IZZN'nin ratlarda ROS üretimi, oksidasyon ve antioksidatif sistem üzerindeki etkileri araştırıldı. ROS, oksidatif stres için önemli bir başlangiç faktörüdür ve vücuttaki artan ROS üretimi, oksidatif stresi tetikler (Combrink ve du Preez 2020, Jia ve ark. 2019, Schieber ve Chandel 2014). Enzimatik (SOD, KAT ve GPx) ve enzimatik olmayan (GSH) antioksidanlar, oksidatif hasara maruz kalan hücrelerin korunmasında önemli bir rol oynarlar (Eldutar ve ark. 2017). Çoklu doymamış yağ asitlerinin son ürünü olan MDA, bir lipit peroksidasyon ürünüdür Serbest radikallerin aşı11 üretimi lipit peroksidasyonuna yol açar, çünkü lipitler hücre zarının en önemli bileşenidir (Aksu ve ark. 2017, Jia ve ark. 2019). GSH düzeylerinin azalmas1, SOD, GPx ve KAT aktivitesinin azalmasi ile vücuttaki artan MDA, serbest radikaller ve reaktif oksijen türleri (ROS) gibi lipit peroksidasyon toksik yan ürünlerini artırarak oksidatif stres, lipit peroksidasyon hasarina neden olur (Cho ve ark. 2015, Jia ve ark. 2019, Xiang ve ark. 2017, You ve ark. 2014). Çalışmada enzimatik ve non-enzimatik enzim aktivitelerinde meydana gelen azalma ve artan MDA düzeyleri, IZZN uygulamasindan sonra ciddi bir oksidatif stresin oluştuğunu göstermektedir. Bununla birlikte, IZN ile birlikte KRS uygulaması akciğer dokularındaki SOD, KAT ve GPx enzim aktivitelerinde önemli bir artış sağladığı gözlenmiştir. IZN'nin bu antioksidan enzim aktiviteleri üzerine azaltıcı etkisi önceki çalışmalarda gösterilmiş ve bunun muhtemelen İN'nin oksidan-antioksidan dengeyi bozarak bakteriyi etkisiz hale getirme çabasından kaynaklandığ şeklinde yorumlanmıştır (Ahadpour ve ark. 2016, Karakurt ve ark. 2019, Raghu ve Karthikeyan 2016). Ayrıca farklı 
çalışmalarda farklı flavonoid türevi antioksidanların MDA düzeyini azalttığı, GSH düzeyi ile GPx, SOD ve KAT enzim aktivitelerini artırdığ1 bildirilmiştir (Aksu ve ark. 2019, Benzer ve ark. 2018, Çelik ve ark. 2020, Kandemir ve ark. 2020). Sunulan çalışmada da benzer şekilde IZN ile birlikte KRS uygulanmas1 MDA düzeylerini azaltıp, GSH düzeyleri ile GPx, SOD ve KAT enzim aktivitelerini ise artırmıstır.

Bir transkripsiyon faktörü olan NF- $\varkappa \mathrm{B}$, hücresel stres arttığında, ROS üretildiğinde ve DNA hasar1 oluştuğunda hücre döngüsü değişikliklerinin yanı sıra birçok işlev görür ve yangı belirteçlerini tetikleyerek yangisal süreci hizlandirır (Agca ve ark. 2014). NFxB'nin düzensizliği, çeşitli enflamatuar hastalıklar ve kanseri içeren çeşitli patolojik durumlarla ilişkilendirilmiştir (Benzer ve ark. 2018). Sunulan çalışmada IZZN uygulamasının rat akciğerlerinde NF$x \mathrm{~B}$ seviyelerinin immunhistokimyasal değerlendirilmesinde yükseldiği ve yangisal sürecin hızlandığ1 görülmektedir. Yapılan farklı çalışmalarda da IZN'nin benzer şekilde NF- $x \mathrm{~B}$ seviyelerinin arttı̆ğ bildirilmiştir (Çelik ve ark. 2020, Wali ve ark. 2019, Zhang ve ark. 2019).

Nrf-2, antioksidan ve sitoprotektif proteinlerin ekspresyonunu düzenleyerek ROS kaynaklı oksidatif hasara karş1 hücreleri koruyan bir transkripsiyon faktörüdür (Mahmoud ve ark. 2020). Nrf-2 aktivasyonu oksidatif hasarı azaltmak için, hücreleri apoptozise karşı koruyan hem faz II ve HO-1 gibi antioksidatif enzimlerin ekspresyonunu arttırır (Abass ve ark. 2016, Dai ve ark. 2016).

HO, hem molekülünü parçalayarak enzimatik olarak bilirubine dönüştürür ve serbest demir, karbon monoksit ve biliverdin oluşumunu sağlar. HO-1 izozimi, substrat hem, oksidatif stres ve fenolik bileşikler dahil olmak üzere çok çeşitli uyaranlarla transkripsiyonel olarak düzenlenir (Guzmán-Beltrán ve ark. 2008). Nrf-2/HO-1 sinyalleme yolu, çok çeşitli uyaranlara yanit olarak bir dizi antioksidan genin ekspresyonunu düzenler ve hücreyi oksidatif strese karş1 korur (Surh ve ark. 2008). Yapılan çalışmada, IZN uygulamas1 Nrf-2 ve HO-1 mRNA transkript seviyesini artırmıştır. Literatür taraması yapıldığında bazı çalışmalarda IZN uygulamasının Nrf-2 ekspresyonunu azalttığ1 öne sürülmüştür. Ancak bu sonucun tam tersini ortaya koyan çalışmalarda mevcuttur. Yani IZN'nin Nrf-2 yolağ1 üzerine olan etkisi hakkında farklı sonuçlar bulunmaktadır. IZN uygulaması sonucu mRNA transkript seviyesinin azalma sebeplerinden biri IZN'nin ilgili gende post transkripsiyonel modifikasyona uğratması olabilir. Ayn zamanda epigenetik modifikasyonlarda ve post transkripsiyonel düzenlemede rol alan kodlanmayan RNA'lar (miRNA gibi) bu sonucun sebepleri arasinda say1labilir (Jin et al. 2017, Verma ve ark. 2018, Wang ve ark. 2018, Zhang ve ark. 2019).
Sonuç olarak IZN'nin akciğer dokusunda oksidanantioksidan dengeyi bozarak hasara neden olduğu, inflamasyonu artırdığ1 gözlenmiş, KRS'nin ise antioksidan ve anti-inflamatuar etki göstererek IZN kaynaklı bu hasarı azalttığı tespit edilmiştir. Konu ile ilgili yapılacak ileri düzey çalışmalar ile IZN kaynaklı akciğer hasarını azaltmada ya da engellemede KRS'nin alternatif tedavi yöntemi olarak yerini alacağ1 ve konuyla ilgili farklı çalışmalara katkı sağlayacağı düşünülmektedir.

Çıkar Çatışması: Yazarlar, çıkar çatışması olmadığını beyan eder.

\section{KAYNAKLAR}

Abass MA, Elkhateeb SA, El-baset SAA, Kattaia AA, Mohamed EM, Atteia HH. Lycopene ameliorates atrazine-induced oxidative damage in adrenal cortex of male rats by activation of the $\mathrm{Nrf} 2 / \mathrm{HO}-1$ pathway Environ Sci Pollut. 2016; 23:15262-15274.

Aebi H. Catalase. In: Methods of enzymatic analysis. Elsevier, pp 1974; 2:673-684.

Agca CA, Tuzcu M, Hayirli A, Sahin K. Taurine ameliorates neuropathy via regulating $\mathrm{NF}-x \mathrm{~B}$ and $\mathrm{Nrf} 2 / \mathrm{HO}-1$ signaling cascades in diabetic rats Food Chem Toxicol. 2014; 71:116-121.

Ahadpour M, Eskandari MR, Mashayekhi V, Haj Mohammad Ebrahim Tehrani K, Jafarian I, Naserzadeh P, Hosseini M-J. Mitochondrial oxidative stress and dysfunction induced by isoniazid: study on isolated rat liver and brain mitochondria Drug Chem Toxicol. 2016; 39:224-232.

Aksu E, Kandemir F, Özkaraca M, Ömür A, Küçükler S, Çomaklı S. Rutin ameliorates cisplatin-induced reproductive damage via suppression of oxidative stress and apoptosis in adult male rats Andrologia 2017; 49:12593-12601.

Aksu EH, Kandemir FM, Yıldırım S, Küçükler S, Dörtbudak MB, Çağlayan C, Benzer F. Palliative effect of curcumin on doxorubicin-induced testicular damage in male rats J Biochem Mol Toxic. 2019; 33:22384-22392.

Basheer AS, Siddiqui A, Paudel YN, Hassan MQ, Imran M, Najmi AK, Akhtar M. Hepatoprotective and antioxidant effects of fish oil on isoniazid-rifampin induced hepatotoxicity in rats Pharma Nutrition 2017; 5:29-33.

Benzer F, Kandemir FM, Kucukler S, Comaklı S, Caglayan C. Chemoprotective effects of curcumin on doxorubicininduced nephrotoxicity in wistar rats: by modulating inflammatory cytokines, apoptosis, oxidative stress and oxidative DNA damage Arch Physiol Biochem. 2018; 124:448-457.

Benzer F, Kandemir FM, Ozkaraca M, Kucukler S, Caglayan C. Curcumin ameliorates doxorubicin-induced cardiotoxicity by abrogation of inflammation, apoptosis, oxidative DNA damage, and protein oxidation in rats J Biochem Mol Toxic. 2018; 32:22030-22037.

Caglayan C, Kandemir FM, Darendelioğlu E, Yıldırım S, Kucukler S, Dortbudak MB. Rutin ameliorates mercuric chloride-induced hepatotoxicity in rats via interfering with oxidative stress, inflammation and apoptosis J Trace Elem Med Bio. 2019; 56:60-68.

Chepelev NL, Zhang H, Liu H, McBride S, Seal AJ, Morgan TE, Finch CE, Willmore WG, Davies KJ, Forman 
HJ. Competition of nuclear factor-erythroid 2 factors related transcription factor isoforms, Nrf1 and Nrf2, in antioxidant enzyme induction Redox Biol. 2013; 1:183189.

Cho YJ, Park SB, Han M. Di-(2-ethylhexyl)-phthalate induces oxidative stress in human endometrial stromal cells in vitro Mol Cell Endocrinol. 2015; 407:9-17.

Choi YH. Activation of the Nrf2/HO-1 signaling pathway contributes to the protective effects of coptisine against oxidative stress-induced DNA damage and apoptosis in HaCaT keratinocytes Gen Physiol Biophys. 2019; 38:281.

Chowdhury A, Santra A, Bhattacharjee K, Ghatak S, Saha DR, Dhali GK. Mitochondrial oxidative stress and permeability transition in isoniazid and rifampicin induced liver injury in mice J Hepatol. 2006; 45:117-126.

Cicek E, Sutcu R, Gokalp O, Yilmaz HR, Ozer MK, Uz E, Ozcelik N, Delibas $\mathbf{N}$. The effects of isoniazid on hippocampal NMDA receptors: protective role of erdosteine Mol Cell Biochem. 2005; 277:131-135.

Comakli S, Sağlam YS, Timurkan MÖ. Comparative detection of bovine herpesvirus-1 using antigen ELISA, immunohistochemistry and immunofluorescence methods in cattle with pneumonia Turk J Vet Anim Sci 2019; 43: 306-313.

Combrink M, du Preez I. Metabolomics describes previously unknown toxicity mechanisms of isoniazid and rifampicin Toxicol Lett. 2020; 332:104-110.

Cunha L, Rodrigues S, Rosa da Costa AM, Faleiro L, Buttini F, Grenha A. Inhalable chitosan microparticles for simultaneous delivery of isoniazid and rifabutin in lung tuberculosis treatment Drug Dev Ind Pharm.i 2019; 45:1313-1320.

Çelik H, Kandemir FM, Caglayan C, Özdemir S, Çomaklı S, Kucukler S, Yardım A. Neuroprotective effect of rutin against colistin-induced oxidative stress, inflammation and apoptosis in rat brain associated with the CREB/BDNF expressions Mol Biol Rep. 2020; 47:20232034.

Çelik H, Kucukler S, Çomaklı S, Özdemir S, Caglayan C, Yardım A, Kandemir FM. Morin attenuates ifosfamideinduced neurotoxicity in rats via suppression of oxidative stress, neuroinflammation and neuronal apoptosis Neuro'Toxicology 2020; 76:126-137.

Çomakli S, Özdemir S, Değirmençay Ş. Canine distemper virus induces downregulation of GABA A, GABA B, and GAT1 expression in brain tissue of dogs. Arch Virol 2020; 1-11.

Dai C, Li B, Zhou Y, Li D, Zhang S, Li H, Xiao X, Tang S. Curcumin attenuates quinocetone induced apoptosis and inflammation via the opposite modulation of Nrf2/HO-1 and NF-kB pathway in human hepatocyte L02 cells Food Chem Toxicol. 2016; 95:52-63.

Eftekhari A, Heidari R, Ahmadian E, Eghbal MA. Cytoprotective Properties of Carnosine against IsoniazidInduced Toxicity in Primary Cultured Rat Hepatocytes Pharm Sci. 2018; 24:257.

Eldutar E, Kandemir FM, Kucukler S, Caglayan C. Restorative effects of Chrysin pretreatment on oxidantantioxidant status, inflammatory cytokine production, and apoptotic and autophagic markers in acute paracetamol-induced hepatotoxicity in rats: An experimental and biochemical study $\mathrm{J}$ Biochem Mol Toxic. 2017; 31:21960-21966.

Endo T, Saito T, Nakayama M, Ohse H, Watanabe S, Tamai S, Hasegawa S. A case of isoniazid-induced pneumonitis. Nihon Kokyuki Gakkai zasshi= the journal of the Japanese Respiratory Society. 1998; 36:100-105.

Guzmán-Beltrán S, Espada S, Orozco-Ibarra M, PedrazaChaverri J, Cuadrado A. Nordihydroguaiaretic acid activates the antioxidant pathway $\mathrm{Nrf} 2 / \mathrm{HO}-1$ and protects cerebellar granule neurons against oxidative stress Neurosci Lett. 2008; 447:167-171.

Han Mc, Durmuş As, Sağliyan A, Günay C, Özkaraca M, Kandemir FM, Çomaklı S, Öztopalan DF. Effects of Nigella sativa and Hypericum perforatum on wound healing Turk J Vet Anim Sci. 2017; 41: 99-105.

Jia Z-1, Cen J, Wang J-b, Zhang F, Xia Q, Wang X, Chen Xq, Wang R-c, Liu K-c, Zhang Y. Mechanism of isoniazid-induced hepatotoxicity in zebrafish larvae: Activation of ROS-mediated ERS, apoptosis and the Nrf2 pathway Chemo. 2019; 227:541-550.

Jin SW, Hwang YP, Choi CY, Kim HG, Kim SJ, Kim Y, Chung YC, Lee KJ, Jeong TC, Jeong HG. Protective effect of rutaecarpine against $t$-BHP-induced hepatotoxicity by upregulating antioxidant enzymes via the CaMKII-Akt and Nrf2/ARE pathways Food Chem Toxicol. 2017; 100:138-148.

Kandemir FM, Yıldırım S, Kucukler S, Caglayan C, Darendelioğlu E, Dortbudak MB. (b) Protective effects of morin against acrylamide-induced hepatotoxicity and nephrotoxicity: A multi-biomarker approach Food Chem Toxicol. 2020; 138:111190-111201.

Kandemir FM, Kucukler S, Eldutar E, Caglayan C, Gülçin İ. Chrysin protects rat kidney from paracetamol-induced oxidative stress, inflammation, apoptosis, and autophagy: a multi-biomarker approach. Sci Pharm. 2017; 85(1): 4

Karakurt Y, Süleyman H, Keskin Cimen F, Tasli G, Ucak T, Icel E, Kurt N. The effects of lutein on optic nerve injury induced by ethambutol and isoniazid: an experimental study Cutan Ocul Toxicol. 2019; 38:136140.

Kilic T, Ciftci O, Cetin A, Kahraman H. Preventive effect of chrysin on bleomycin-induced lung fibrosis in rats Inflammation. 2014; 37:2116-2124.

Kunichika N, Miyahara N, Kotani K, Takeyama H, Harada M, Tanimoto M. Pneumonitis induced by rifampicin Thorax. 2002; 57: 1000-1001.

Liang Z, Ni R, Zhou J, Mao S. Recent advances in controlled pulmonary drug delivery Drug Discov. Today. 2015; 20:380-389.

Livak KJ, Schmittgen TD. Analysis of relative gene expression data using real-time quantitative PCR and the $2-\Delta \Delta C T$ method Methods 2001; 25:402-408.

Lowry OH, Rosebrough NJ, Farr AL, Randall RJ. Protein measurement with the Folin phenol reagent J Biol Chem. 1951; 193:265-275.

Mahmoud AM, Hussein OE, Hozayen WG, Bin-Jumah M, Abd El-Twab SM. Ferulic acid prevents oxidative stress, inflammation, and liver injury via upregulation of Nrf2/HO-1 signaling in methotrexate-induced rats Environ Sci Pollut Res Int. 2020; 27:7910-7921.

Matkovics B. Determination of enzyme activity in lipid peroxidation and glutathione pathways Lab Diag. 1988; 15:248-250.

Mehri S, Karami HV, Hassani FV, Hosseinzadeh H. Chrysin reduced acrylamide-induced neurotoxicity in both in vitro and in vivo assessments Iran Biomed J. 2014; 18:101.

Migita K, Umeno T, Miyagawa K, Izumi Y, Sasaki E, Kakugawa T, Ito M, Kinoshita A, Miyashita T. 
Development of interstitial pneumonia in a patient with rheumatoid arthritis induced by isoniazid for tuberculosis chemoprophylaxis Rheumatol Int. 2012; 32:1375-1377.

Nishizawa Y, Yasui M, Yamamori C, Tagami A, Fujimura M, Nakao S. A case of successful desensitization therapy for isoniazid-induced pneumonitis Nihon Kokyuki Gakkai zasshi $=$ the journal of the Japanese Respiratory Society. 2004; 42:649-654.

Ohta K, Nagase H. Drug-induced interstitial lung disease Nihon Rinsho. 2012; 70:517-520.

Organization WH. Global tuberculosis report 2013. WHO,

Park EJ, Kim YM, Park SW, Kim HJ, Lee JH, Lee D-U, Chang KC. Induction of HO-1 through p38 MAPK/Nrf2 signaling pathway by ethanol extract of Inula helenium L. reduces inflammation in LPS-activated RAW 264.7 cells and CLP-induced septic mice Food Chem Toxicol. 2013; 55:386-395.

Placer ZA, Cushman LL, Johnson BC. Estimation of product of lipid peroxidation (malonyl dialdehyde) in biochemical systems Anal Biochem. 1966; 16:359-364.

Plit ML, Theron AJ, Fickl H, Van Rensburg CEJ, Pendel S, Anderson R. Influence of antimicrobial chemotherapy and smoking status on the plasma concentrations of vitamin $C$, vitamin $\mathrm{E}, \beta$-carotene, acute phase reactants, iron and lipid peroxides in patients with pulmonary tuberculosis Int J Tuberc Lung Dis. 1998; 2: 590-596.

Raghu R, Karthikeyan S. Zidovudine and isoniazid induced liver toxicity and oxidative stress: Evaluation of mitigating properties of silibinin Environ Toxicol Pharmacol. 2016; 46:217-226.

Ruan L-Y, Fan J-T, Hong W, Zhao H, Li M-H, Jiang L, Fu Y-H, Xing Y-X, Chen C, Wang J-S. Isoniazid-induced hepatotoxicity and neurotoxicity in rats investigated by 1H NMR based metabolomics approach Toxicol Lett. 2018; 295:256-269.

Schieber M, Chandel NS. ROS function in redox signaling and oxidative stress Curr Biol. 2014; 24:453-462.

Sedlak J, Lindsay RH. Estimation of total, protein-bound, and nonprotein sulfhydryl groups in tissue with Ellman's reagent Anal Biochem. 1968; 25:192-205.

Sun Y, Oberley LW, Li Y. A simple method for clinical assay of superoxide dismutase Clin Chem. 1988; 34:497-500.

Surh Y-J, Kundu JK, Na H-K. Nrf2 as a master redox switch in turning on the cellular signaling involved in the induction of cytoprotective genes by some chemopreventive phytochemicals Planta Med. 2008; 74:1526-1539.

Suzuki N, Ohno S, Takeuchi Y, Yamanaka K, Sugiyama Y, Kitamura S. A case of isoniazid (INH)-induced pneumonitis The Japanese journal of thoracic diseases 1992; 30:1563-1568.

Temel Y, Kucukler S, Yıldırım S, Caglayan C, Kandemir FM. Protective effect of chrysin on cyclophosphamideinduced hepatotoxicity and nephrotoxicity via the inhibition of oxidative stress, inflammation, and apoptosis. Naunyn-Schmiedeberg's Arch. Pharmacol. 2020; 393(3):325-337.

Verma AK, Yadav A, Singh SV, Mishra P, Rath SK. Isoniazid induces apoptosis: Role of oxidative stress and inhibition of nuclear translocation of nuclear factor (erythroidderived 2)-like 2 (Nrf2) Life Sci. 2018; 199:23-33.

Wali AF, Mushtaq A, Rehman MU, Akbar S, Masoodi MH. Amelioration of Rifampicin and Isoniazid Induced Liver Oxidative Damage and Inflammation Response by
Propolis Extracts in Rodent Model Jou of Biolo Acti Prod from Nat 2019; 9:57-66.

Wang J, Luo W, Li B, Lv J, Ke X, Ge D, Dong R, Wang C, Han Y, Zhang C. 2018. Sagittaria sagittifolia polysaccharide protects against isoniazid-and rifampicininduced hepatic injury via activation of nuclear factor E2related factor 2 signaling in mice J Ethnopharmacol. 2018; 227:237-245.

Xiang N, Zhao C, Diao X, Han Q, Zhou H. Dynamic responses of antioxidant enzymes in pearl oyster Pinctada martensii exposed to di (2-ethylhexyl) phthalate (DEHP) Environ Toxicol Pharmacol. 2017; 54:184-190.

Yang Z, Guan Y, Li J, Li L, Li Z. Chrysin attenuates carrageenan-induced pleurisy and lung injury via activation of SIRT1/NRF2 pathway in rats Eur J Pharmacol. 2018; 836:83-88.

You H, Chen S, Mao L, Li B, Yuan Y, Li R, Yang X. The adjuvant effect induced by di-(2-ethylhexyl) phthalate (DEHP) is mediated through oxidative stress in a mouse model of asthma Food Chem Toxicol. 2014; 71:272-281.

Zhang D, Xiao Y, Lv P, Teng Z, Dong Y, Qi Q, Liu Z. Edaravone attenuates oxidative stress induced by chronic cerebral hypoperfusion injury: role of ERK/Nrf2/HO-1 signaling pathway Neurol Res. 2018; 40:1-10.

Zhang Q, Zhao Y, Talukder M, Han Y, Zhang C, Li X-N, Li J-L. Di (2-ethylhexyl) phthalate induced hepatotoxicity in quail (Coturnix japonica) via modulating the mitochondrial unfolded protein response and NRF2 mediated antioxidant defense Sci. Total Environ. 2019; 651:885-894.

Zhang Y, Li Y, Li J, Li B, Chong Y, Zheng G, Sun S, Feng F. SIRT1 alleviates isoniazid- induced hepatocyte injury by reducing histone acetylation in the IL-6 promoter region Int Immunopharmacol. 2019; 67:348-355.

Zhang Z, Guo Z, Zhan Y, Li H, Wu S. Role of histone acetylation in activation of nuclear factor erythroid 2related factor $2 /$ heme oxygenase 1 pathway by manganese chloride Toxicol Appl Pharmacol. 2017; 336:94-100. 